Our knowledge of the different forms and locations of gastric ulcer has been made possible only by a careful study of the subjective and objective symptoms and by comparing them with the operative findings. To date we have learned little from other methods, including the $x$-ray. I shall incorporate the essentials of the history of a case referred to me, as the symptoms differ somewhat from those commonly given of ulcer of the stomach, and may aid toward a recognition of chronic ulcer of the posterior wall of the stomach, particularly where its base is adherent to the pancreas or other structures.

\section{REPORT OF CASE}

During the latter part of December, 1910, Dr. A. D. Dunn of Omaha, turned over to me for operation in the Clarkson Hospital a man giving an undoubted history of chronic gastric ulcer. The notes on history and examination are by Dr. Dunn.

History.--"W. HI., policeman, aged 40, married, was first vis ited Oct. 7,1910 . Family history negative. During the past two years, with a gradual onset, there had been, commencing about half an hour after meals, a sense of fulness and heaviness in the epigastrium with some belching; this condition would last one to two hours. The discomfort was greater

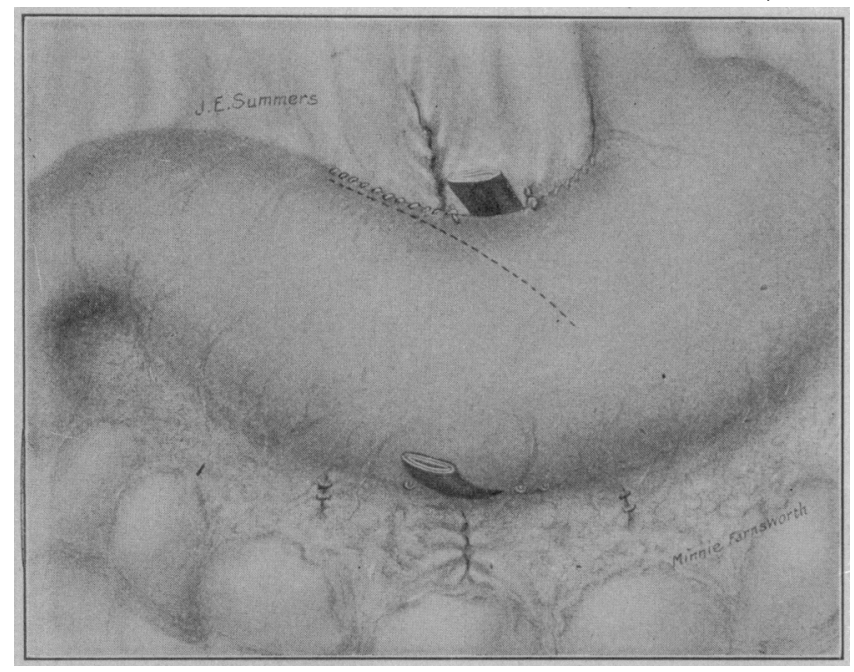

Fig. 3.-Dotted line, sutures in the posterior wall of the stomach the lepailed open $n_{b}$ 's in the gastronepdte and gascrocolic oinentum; igarette drairs.

after a full meal, and was increased by sour vegetables and condiments. One year before the man had vomited blood. For the past two months he had vomited blood frequently and for several weeks blood had been present daily in the vomitus; his stools had been tarry, and he had rapidly grown pale and weak. Blood showed 2,500,000 reds and 30 per cent. hemoglobin: there was marked tenderness in the epigastrium; he complained bitterly of pain across the back, which was worse after eating; there was a hyperesthetic, tender area to the left of the tenth, eleventh and twelfth dorsal vertebræ. The patient was sent to the hospital and put on a Lenhartz diet. The course was completed in six weeks, at the end of which time the blood had disappeared from the stools; vomiting had ceased and he was largely free from pain; he returned home. One night he overate; the epigastric pain recurred with intensity and blood reappeared in the stools; he complained of pain in the region of the heart, which usually commenced between 11 and 12 o'clock at night and lasted until 3 or 4 in the morning. There was intense soreness and heaviness in the testicles, which made it difficult for him to rise from his chair.

Examination.-"Dec. 8, 1910: Patient is much improved in general appearance. There is marked tenderness and rigidity in the epigastrium; the fifth, sixth and seventh interspaces in the nipple line are exquisitely tender, as is the whole right and left dorsal area on both sides from the sixth to the twelfth dorsal vertebræ. Both testicles are hyperesthetic but do not appear abnormal. A test breakfast shows a total acidity of 82; hydrochloric acid, 60 ; blood present. No retention after eight hours from a test meal.

"The patient returned to the hospital and after one week's starvation a modified Lenhartz diet was again instituted. During three weeks there was little improvement; pain persisted to the extent of making his nights miserable and the stools were rarely free from occult blood. As soon as any increase was made in the diet the pain would be aggravated and the occult blood would be in greater evidence. Inasmuch as there had been no satisfactory results from medical treatment, and the patient's physical condition and the blood findings (reds $5,000,000$, whites 5,500 , hemoglobin 85 per cent.) were such as to warrant an operation, it was deemed the proper moment for surgical intervention in an obstinate and persistently bleeding ulcer."

Operation.-I operated on Dr. Dunn's patient in the Clarkson Hospital Jan. 2, 1911. The ulcer was situated on the posterior wall of the stomach; it was large and indurated. The anterior wall of the stomach could be invaginated into the ulcer base to the depth of one-half the length of the last phalanx of the thumb. After the usual application of stomach clamps the gastrohepatic omentum and the gastrocolic omentum were opened as indicated in Figure 1, and with gauze protection the ulcer was freed from firm posterior attachments, in the doing of which I perforated the base, opening the stomach. The ulcer base was so adherent to the pancreas that I am inclined to believe perforation with adhesion had already taken place. The induration extended over and across the lesser curvature; I might designate the ulcer as a "turned saddle." Before the ulcer was excised the cavity of the lesser peritoneum was packed off as indicated in Figure 2, and as it was excised the stomach was lightly stuffed with gauze for further protection of the wound-also shown in Figure 2. Figure 3 illustrates well the line of sutures in the posterior wall; there were two continuous, a through-and-through (not the Connell) and an imbedding musculoperitoneal. Figure 3 also shows the closed gastrohepatic and gastrocolic temporary wounds for technic. Two large cigarette drains were introduced, each to the line of suture in the stomach wall and coming out, the one at the upper end of the abdominal incision and the other at the lower. Our patient has, to date, made a most excellent recovery.

The peculiar pains complained of may be explained by the posterior adhesions. The splenic artery runs along the upper border of the pancreas as a rule, but I have seen one case of fatal hemorrhage from a gastric ulcer which ulcerated into the splenic artery running within the pancreas tissue. Cases of fatal hemorrhage from gastric ulcer have been reported in which the ulcerated splenic artery was the source, but whether or not a variation in the usual position of the vessel was the reason, I am not informed. Brinton sars that 58 per cent. of fatal gastric hemorrhages come from the splenic artery. The possible relation of an ulcer of the posterior wall of the stomach to the splenic artery would suggest extreme gentleness in the freeing of adhesions.

\section{DEFINITE KNOWLEDGE OBTAINED BY MEANS OF THE X-RAY *}

$$
\begin{aligned}
& \text { E. M. SALA, M.D. } \\
& \text { RJCK ISLAND, ILL. }
\end{aligned}
$$

While it is possible for an expert photographer so to alter $x$-ray negatives and prints that they may be made to represent almost anything, yet there can be no question about the $x$-ray's wide range of usefulness in solving the many perplexing problems with which the surgeon is continuously confronted.

* Read before the Western Surgical Association, Chicago, December, 1910 . 


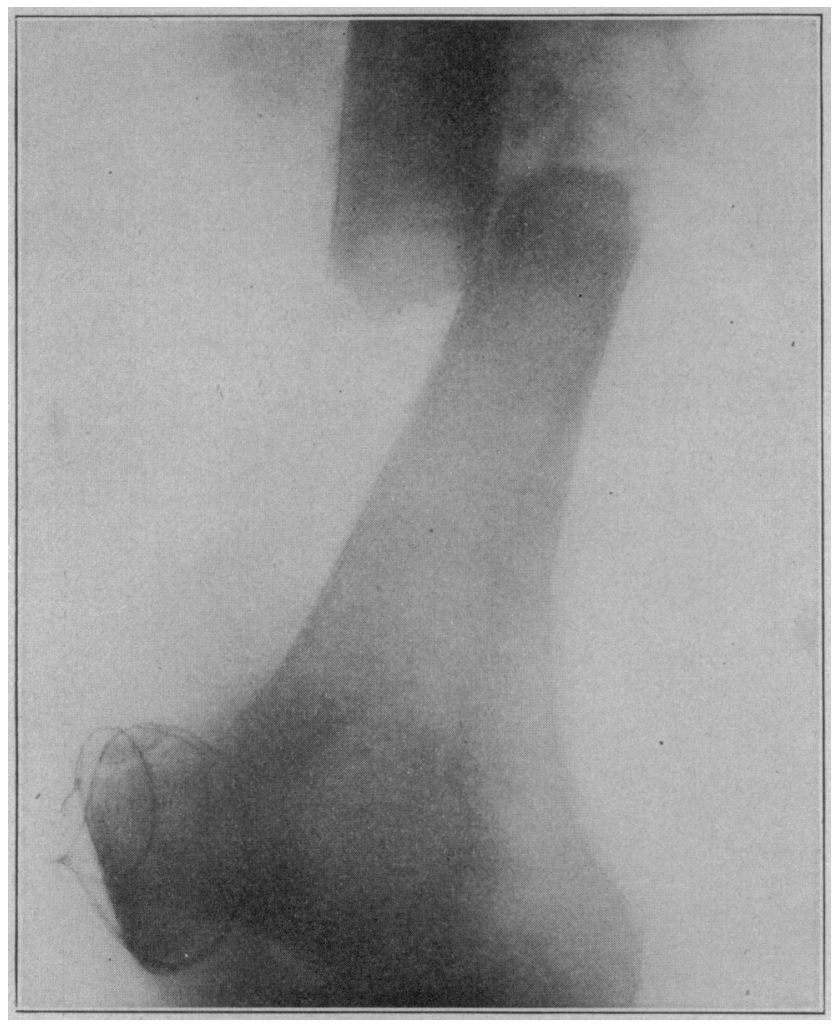

Fig. 1.-This (Case 1) illustrates very well what was considered a fairly good result in fractured femul preceding the time of the $x$-ray. Here we have not to exceed one inch of shortening in a several physicians and thought to be in perfect position.

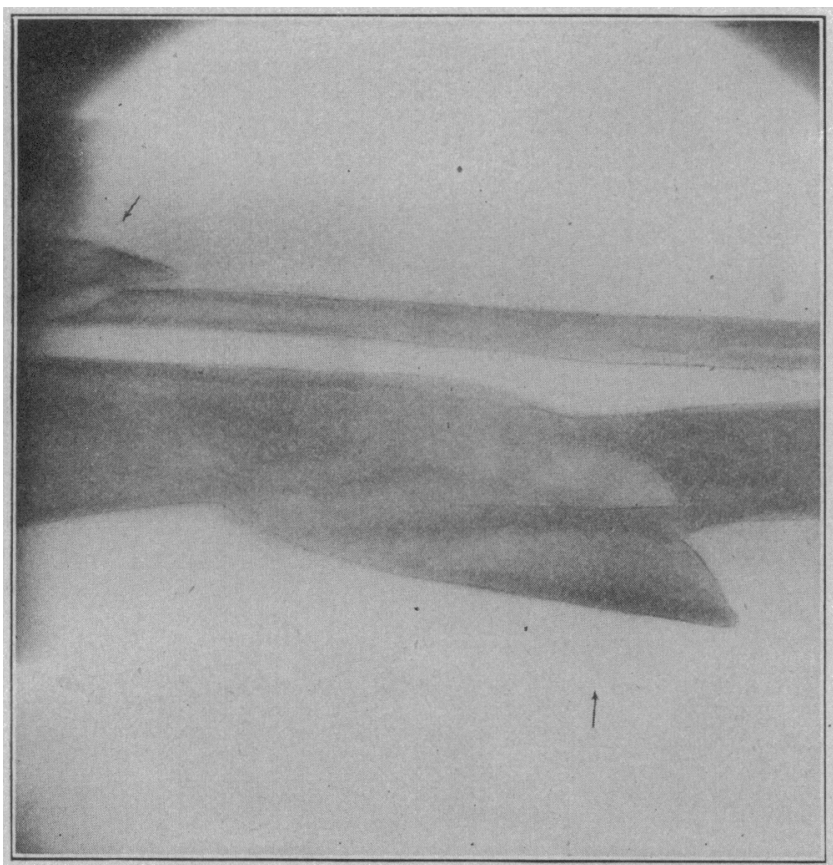

Fig. 3.-Double compound fracture of tibia and comminuted fracture of fibula. This (Case 2) shows how necessary it is to take exposures from two or more directions in order to have a correct understanding of the existing deformity. This patient was injured in an automobile accident and escaped with only his life: he sustained otber serious injuries besides the one here shown. Owing to the shock and other conditions present it was thought best not to the shock and other conditions present it was thought best not to operate on him and readjust the fragments as they should be. was accomplished by the aid of an ambulatory splint and the application of plaster-of-Paris molds.

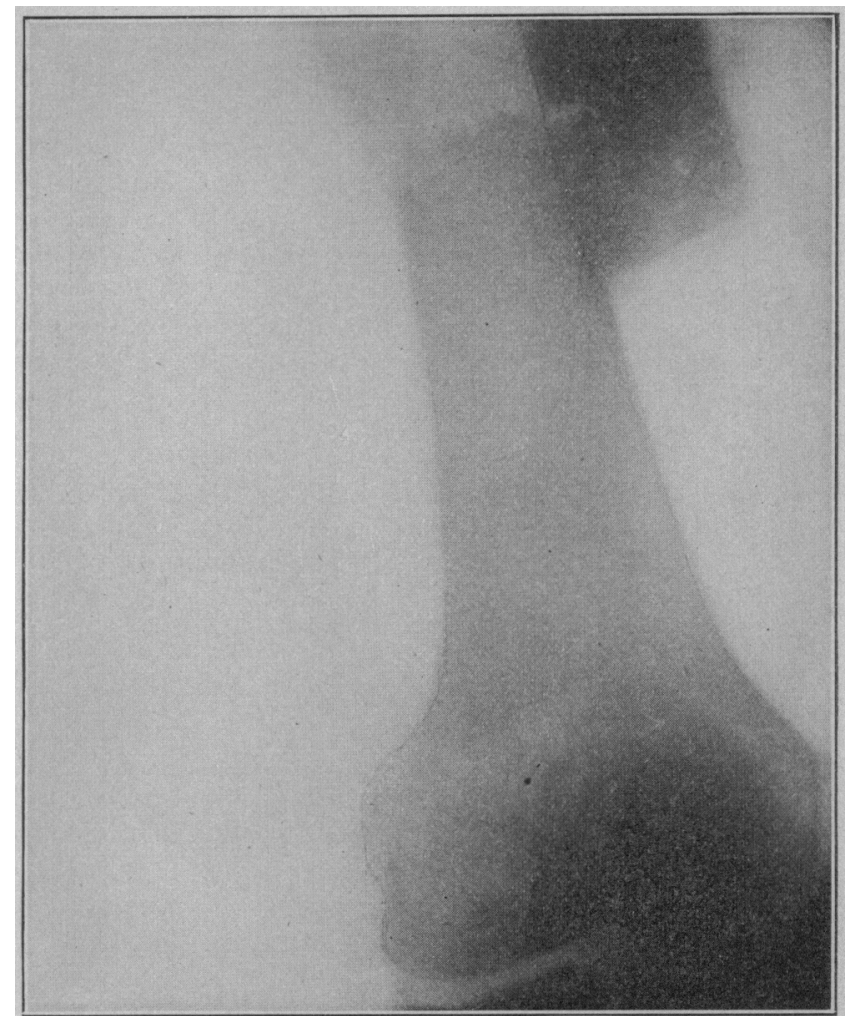

Fig. 2.-Another view of fracture (Case 1) shown in Figure 1 While the patient has a very good resuit for a fractured femur, yet it is not quite what we should expect with the aid of the $x$-ray. In this illustration and in Figure 1 the outlines of the bone have been reenforced in order that they might be clear after reduction and reproduction.

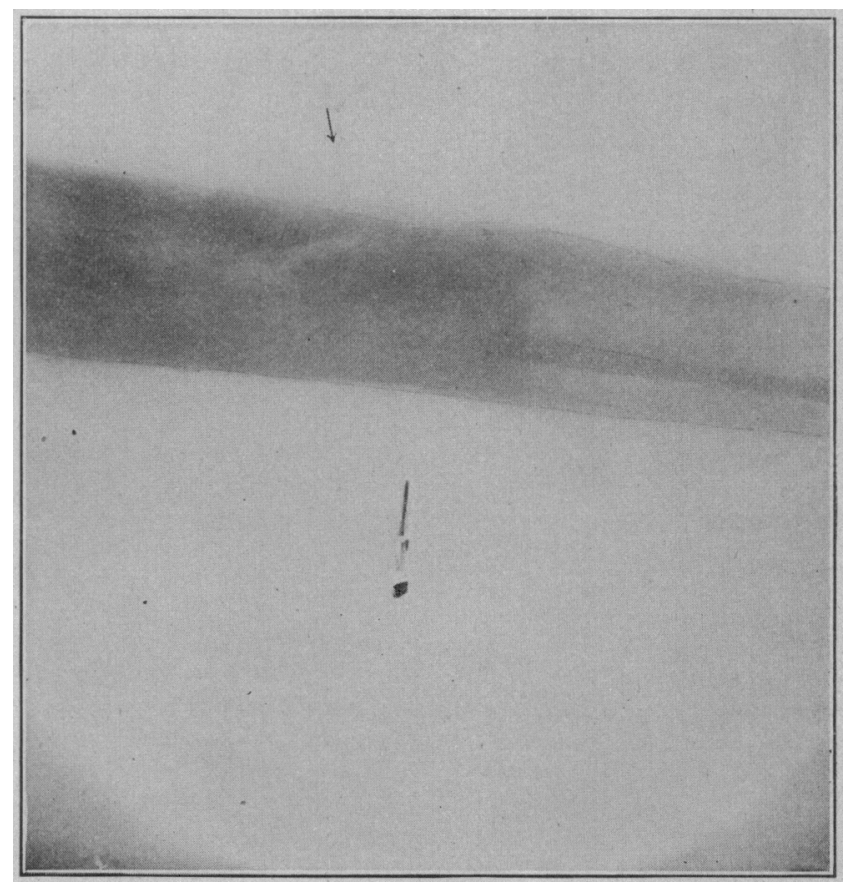

Fig. 4.- Lateral view of double compound comminuted fracture of tibia and fibula (Case 2). The patient now, six months after accident, is walking on the leg without any apparent evidence of shortening. He has discharged some small pieces of bone and has experienced a rather protracted disability, but the result seems as good as we could have obtained by an opelation so far as usefulness is conplaced fragment of bone the fragent pland the whole lof bone, the fiagment has grow to the now and the whole leg seems strongest at what would appear to be its weakest point. In this and Flgure 3 also the outlines of the bone in the radiograph have been reenforced. 


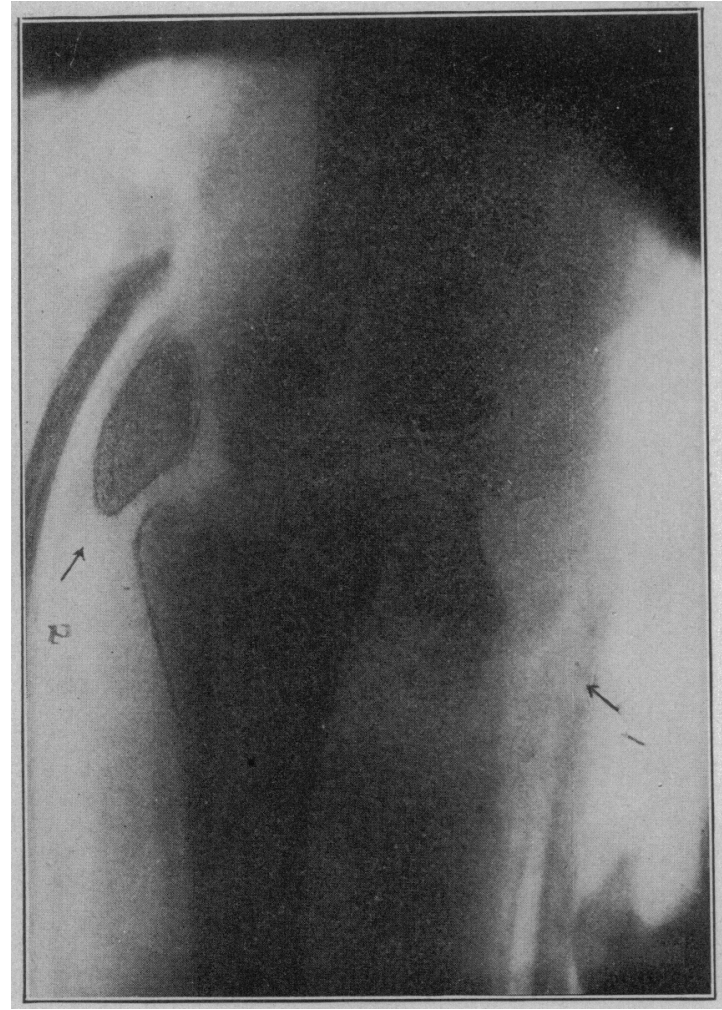

Fig. 5.-Fracture and partial dislocation of left elbow (Case 3 ). Arrow 1 points to detached external condyle and Arrow 2 to internal condyle. Arm is still in splints after a labored effort by two good physicians to adjust break without operation. This adjust ment is probably as good as it could be without an open operation.

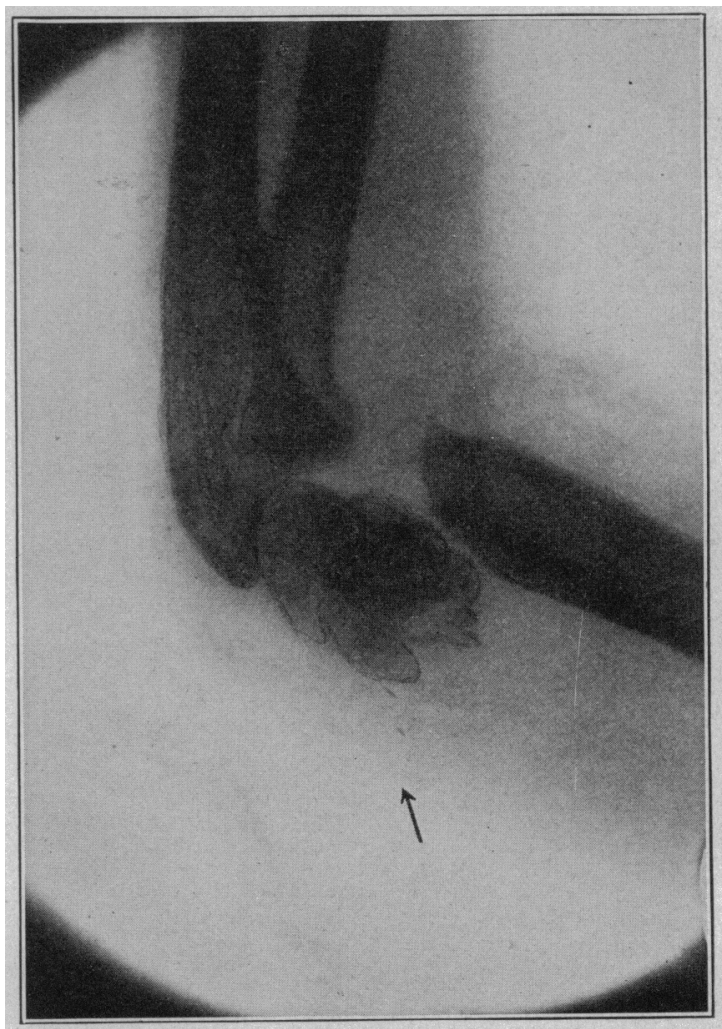

Fig. 6.-Lateral view of same fracture (Case 3 ) of both condyles before wiring, upper fragment protruding through skin. The out lines of the bones have been reenforced in this set of radiographs also.

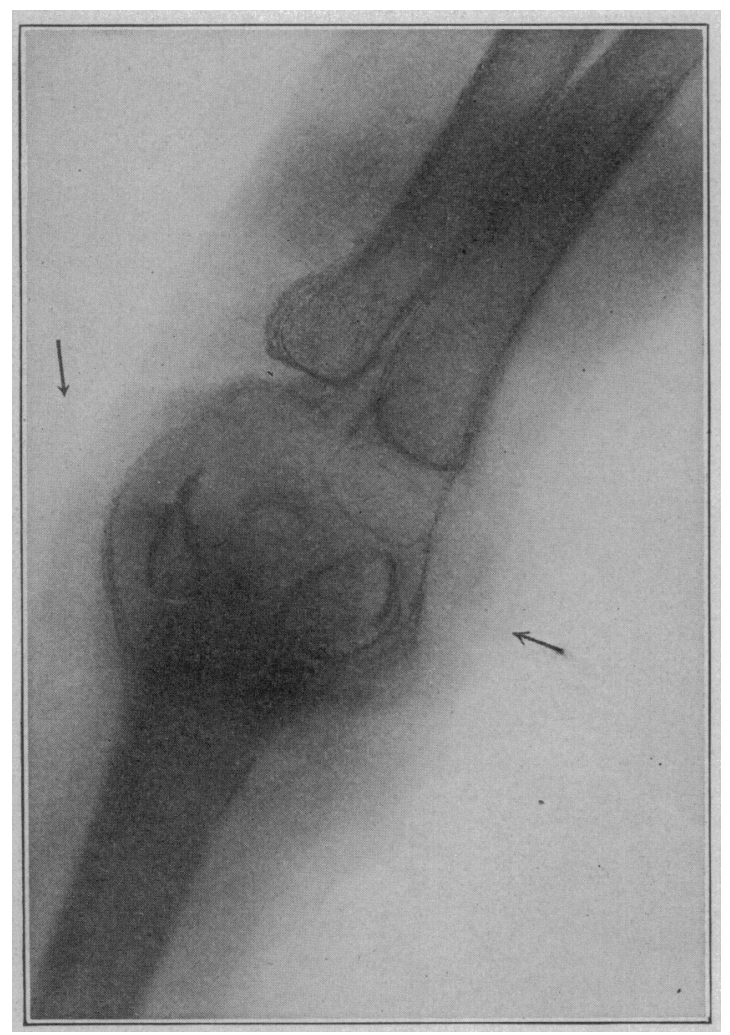

Fig. 7. - Same elbow (Case 3) after adjustment and wiring con dyles in place. It was necessary to open elbow by incisions in three places and tissues were elevated so we could see clear through arm in front of bones. One incision was made where bone had penetrated through skin.

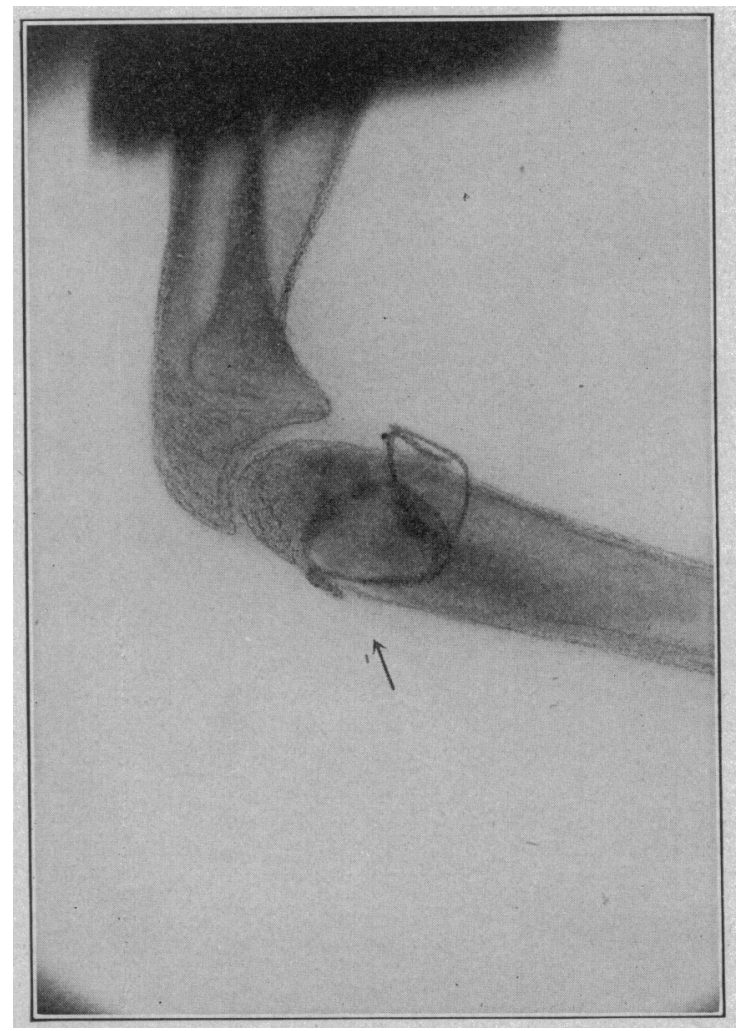

Fig. 8.-Lateral view of same fracture (Case 3) after wiring. Elbow was put in splints and kept quiet for six weeks, no passive motion being permitted until inflammation had entirely subsided. Four months after injury boy has full use of arm. 


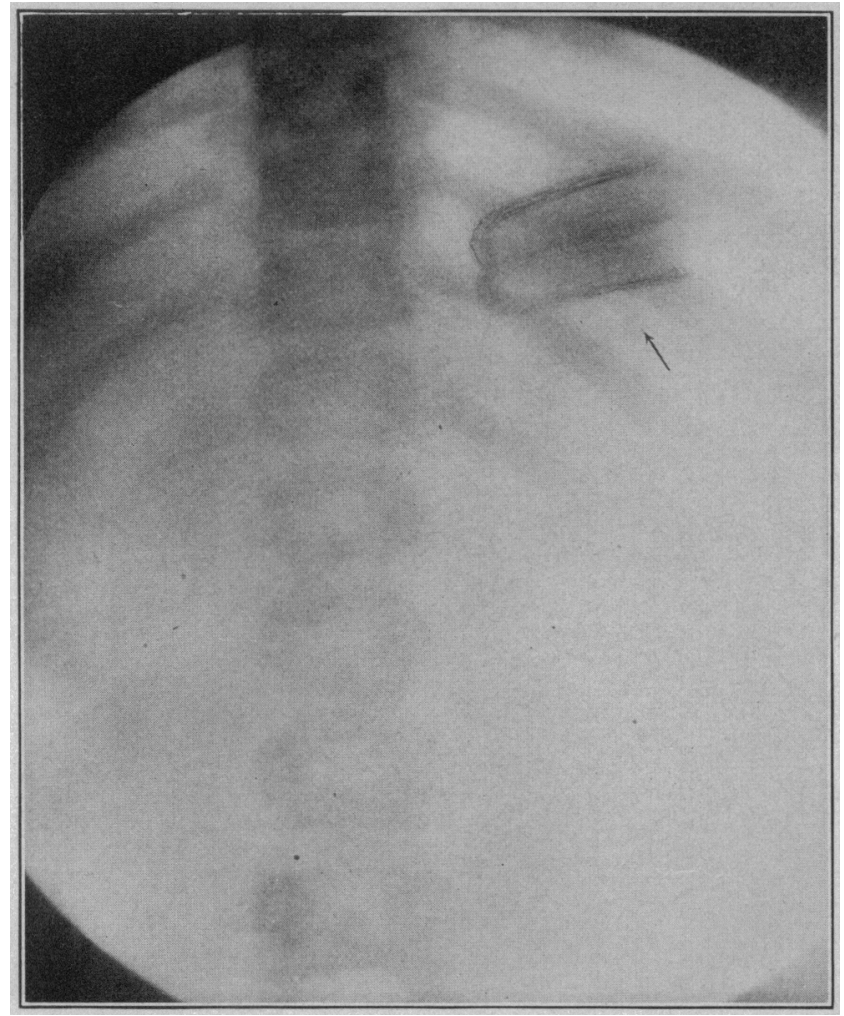

Fig. 9.-A girl, 8 year's old (Case 4), swallowed a fence staple. $A$ skiagraph (not reproduced here), taken three hours afterward, showed the staple being churned about in the stomach. This shows the staple about to lrave the stomach. Here the staple made a half turn while being radiographed and we have a donble view of it. In this set of pictures the outlines of the staple and some of the boncs have been reenforced.

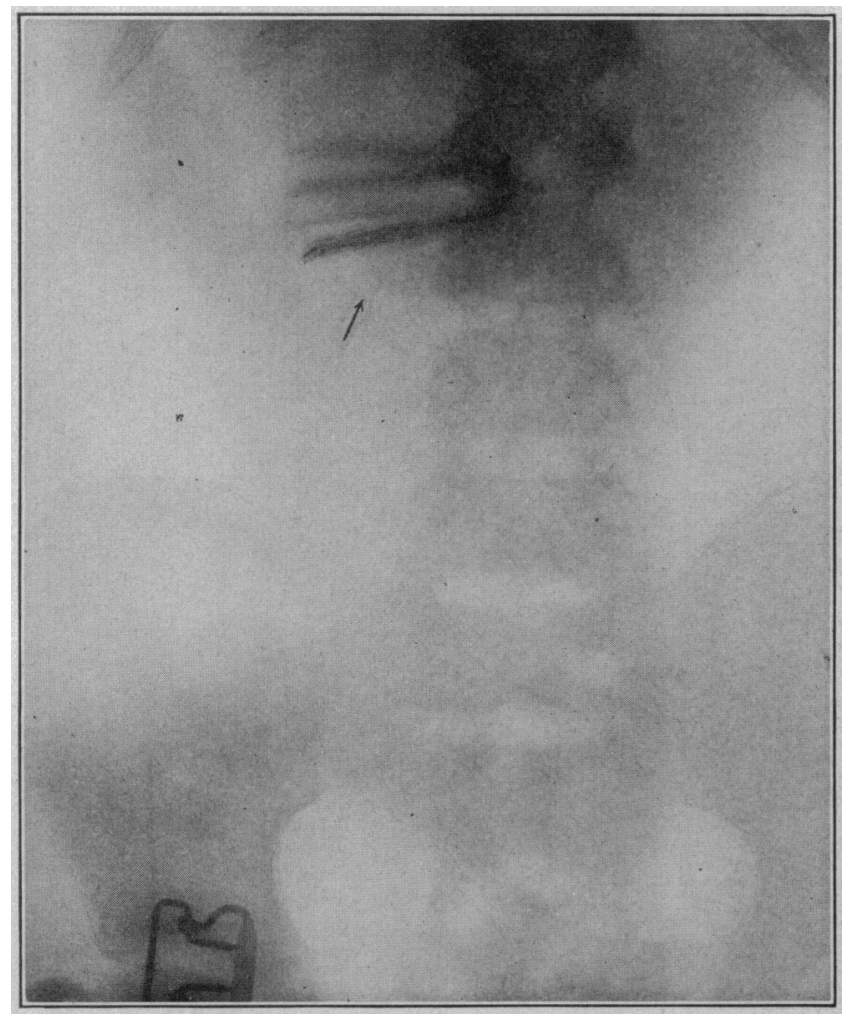

Fig. 11.- Staple in ascending duodenum about the duodenojejunal juncture; it has almost completed a circle; this is also a double view. Figures 9,10 and 11 were all taken during the same hour showing the speed with which such things travel. The staple then had traveled from the uper right-hand corner to the jejunum in one hour's time. or in four hours after being swallowed.

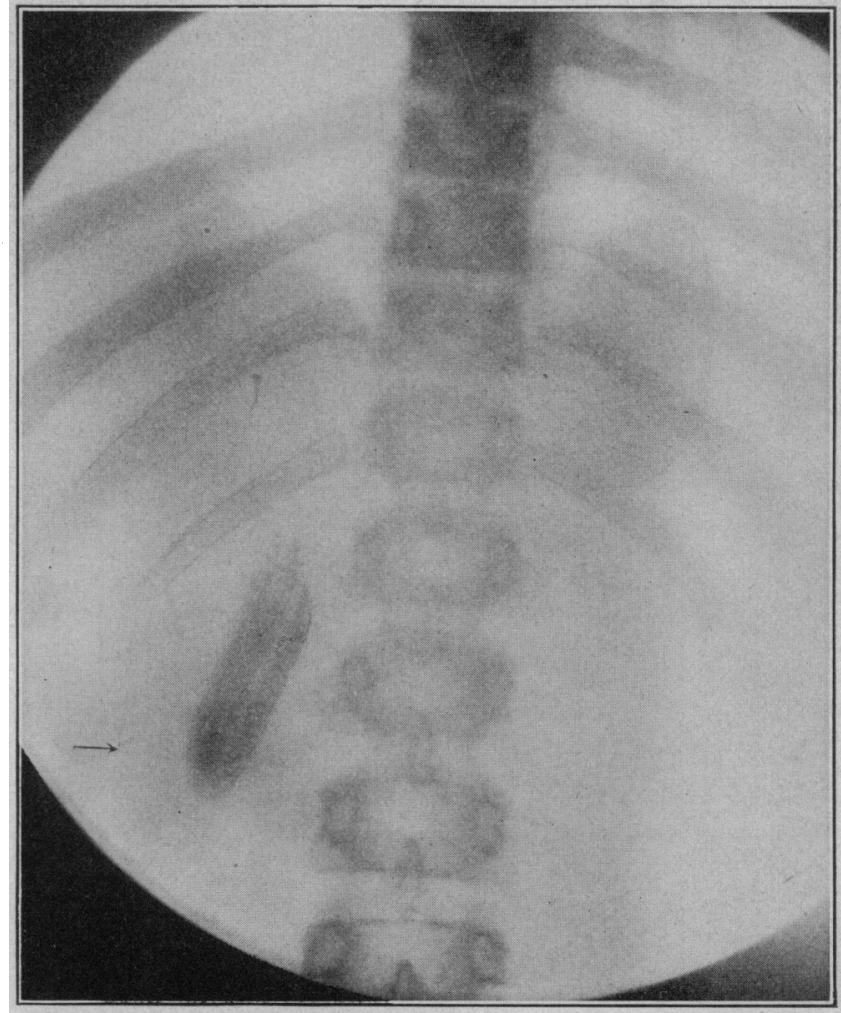

Fig. 10.-This shows the staple traversing the descending duodenum on the opposite side of spine from Figure 9 and down below last floating rib. The staple was not aided in its progress by any form of treatment Herc wo also get a partial double view on account of the peristaltic action of the bowel.

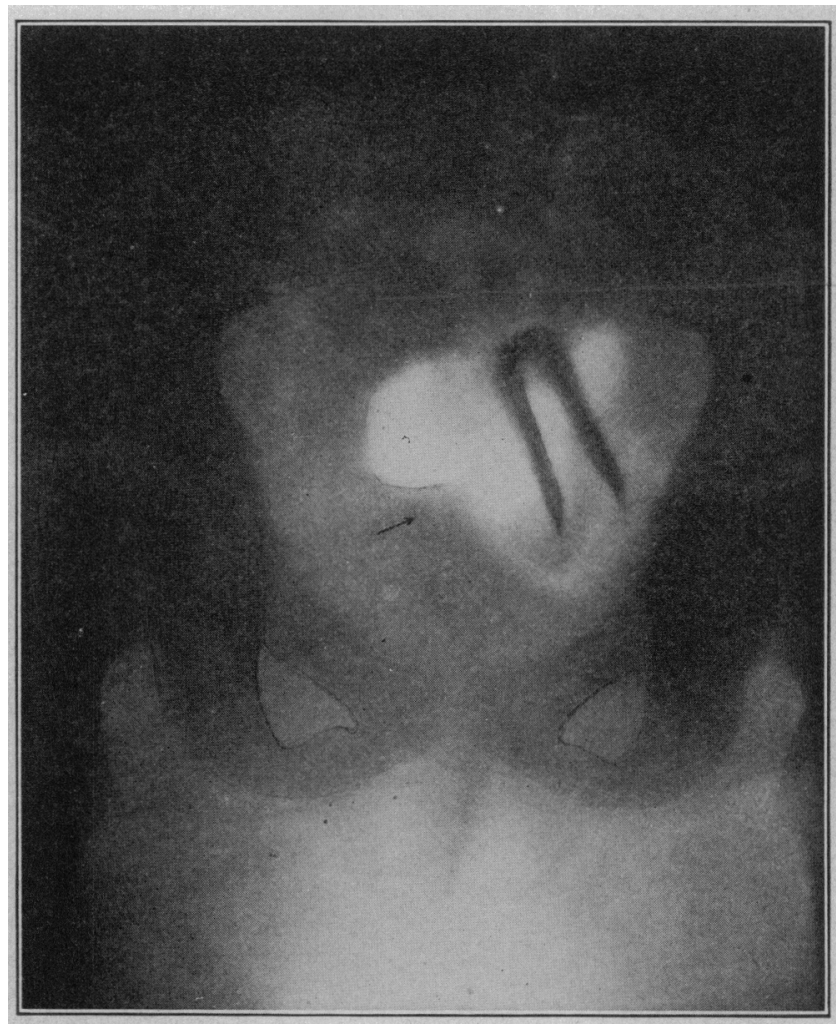

Fig. 12.-This was taken thirty-six hours after Figures 9, 10 and 11 , and shows the staple to better advantage, evidently because it was more stationary. No treatment was given the child except an enema, thirty-nine hours after the staple was swallowed, when the staple was washed away. This plate was exposed to the $x$-ray nine seconds. It appears as though the staple had turned around in the large bowel, but it was evidently procecding arch first and war about to make the loop of the sigmoid. 
An agent for one of our large $x$-ray houses recently said that certain physicians had told him that "the $x$-ray was a thing of the past and it would soon be done away with." Such conclusions can be due only to one of two causes: either these phrsicians have fumbled their own $x$-ray work or some one else has fumbled it for them. troubles just begin. When you have spoilt about two or three hundred plates and punctured half a dozen tubes you begin to realize how little you really did know about the business in the beginning. I spent six years trying to take a picture of a hip-joint before I succeeded in getting one that I would dare exhibit without an

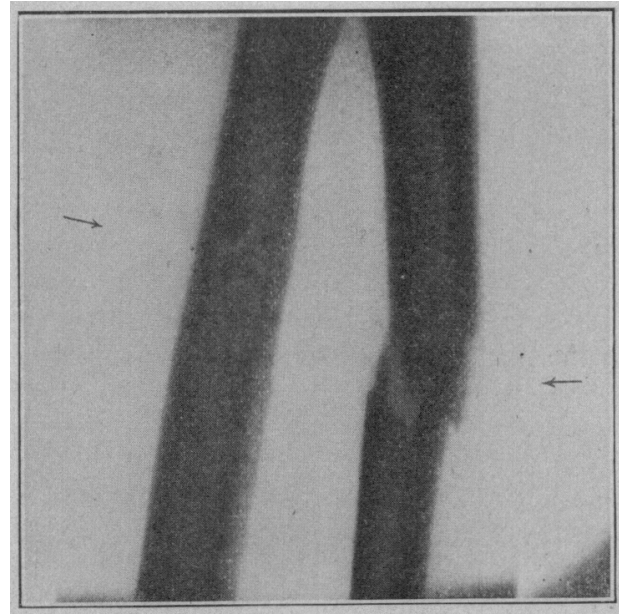

Fig. 13.-Fracture of both bones of forearm (Case 4). Here we have quite clearly demonstrated a condition in fractures of two bones parallel to each other in which it seems almost impossible to secure a porfect coaptation without an operation, beciuse when one bone is purfect the other is out of adjustment, and if the second bone is perfect the otber is out.

Some one has well said: "To read the report of finding a renal calculus, a tuberculous hip or a frontal sinus disease is one thing; to realize the long road of failure and discouragement which the writer traveled to reach that end is quite another." The man who sells you the machine tells you that it will take any old thing at any old time; he puts it in and shows you how it is done; after he is gone your

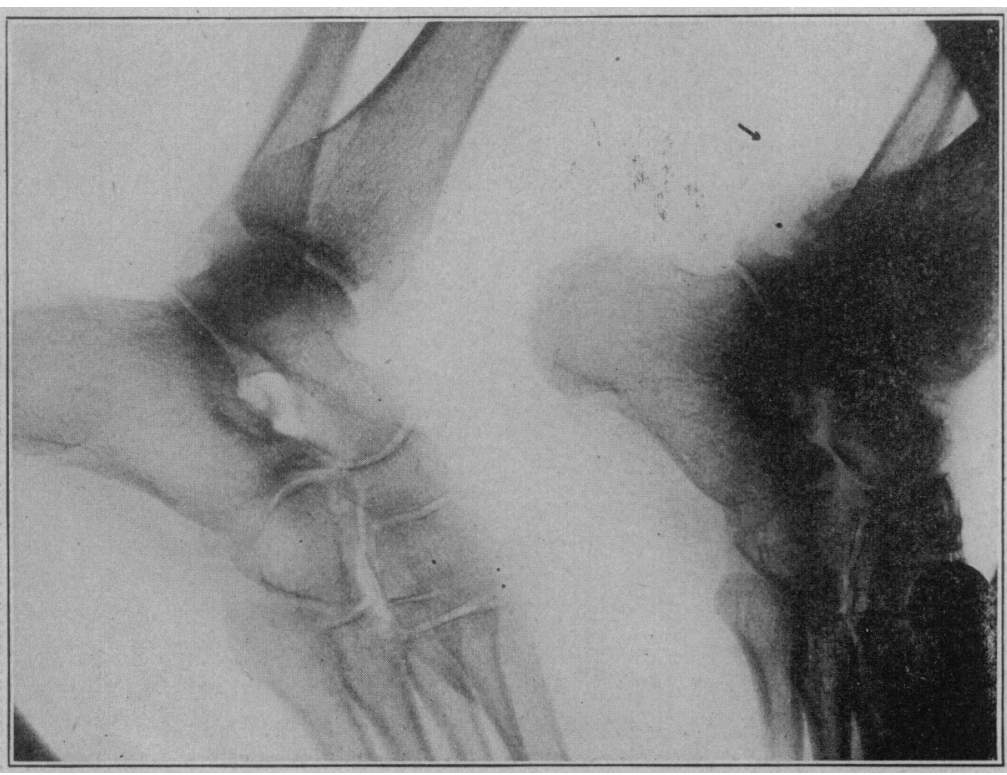

Fig. 15.- Normal ankle on left and sprained ankle (Case 6) on right with particles of tibia broken off. Such injuries tell the reason why some sprained ankles do not recover rapidly, there being a fracture in addition to the sprain. ankles do not recover rapidly, there being a fracture in addition to the sprain. demonstrate how it is possible to develop a negative so that all the soft tissues and even the tendons disappear, the single foot view showing a shadow of the tendo Achillis. The outlines of the particles of broken tibia on the right hav

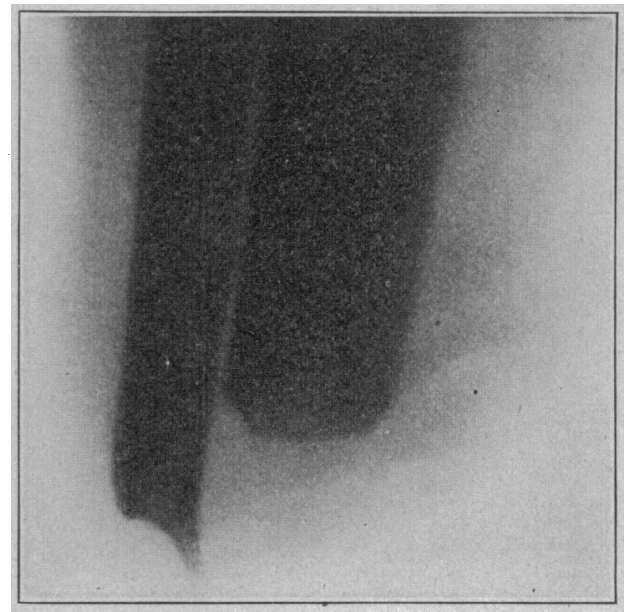

Fig. 16.-Amputated leg (Case 7 ), fibula being left lialf an inch longer than tibia with an additional spicula projecting one-fourth inch further. This leg gave trouble until reamputated and bones made even, which shows the importance of making bones even. If either bone is to be left long it should be the tibia, because it is the larger and the bone that bears the weight of the body, the fibula being only a brace.

apology. Some one has said that "not failure, but low aim, is crime."

The $x$-ray is no longer estopped by the query whether these things can be taken; it is now only how well they can be taken; that is, radiography is a highly dereloped art. Much of our work previous to the $x$-ray was problematical. A fracture would be adjusted so that the part looked all right to the naked eye and allowed to go at that, but to-day it is different. After the fracture is adjusted an $x$-ray is taken, and if the bones are improperly adjusted the fracture is treated accordingly. Time was when a surgeon might say that an injury to a joint was a simple sprain and stick to his opinion without fear of contradiction, but to-day he may be forced to change his opinion when confronted by the $x$-rav findings. It is surely a great source of satisfaction to be in practice in the present age as compared with the many uncertainties which existed in the practice, say twenty years ago.

In frantures the $x$-ray shows us, many times, a very imperfect adjustment of the bones in what had seemed a perfect adjustment when examined without the aid of the $x$-rav. Frequently amputations refuse to heal and it is not always possible for one to say why, without the aid of an $x$-ray. A small piece of bone mav have been left in rounding off the edges of the bone: or it mav be found that the bone was left long when it should have been short. The case shown in the collection here (Figure 16) is a very good illustration of how this happens. Here the sur- 
geon, no doubt, thought that the bones were even; but instead the fibula is half an inch longer than the tibia with a sprig of bone extending down fully half an inch further; this constantly gave trouble until removed. A condition like this may be ascertained without the $x$-ray in a thin subject, but in the average individual it would be rather difficult, previous to operation.

The course of the ureters can be outlined when they contain metal catheters; the stomach can be clearly outlined when injected with bismuth and the work on the thoracic cavity, so beautifully worked out by Beck, makes the knowledge we may obtain with the $x$-ray very extensive. The aid which the $x$-ray bears to a correct diagnosis (within its limits of course) cannot be underestimated. Many of these points, thus hastily referred to, are illustrated by the accompanying radiographs and case reports.

The $x$-ray, when in good working order, is one of the most valued adjuncts to good surgical work we have at our command. It helps to make surgery a more exact science. It gives us a much clearer understanding of our cases and will, eventually, lessen to a great extent the vast number of cripples that were unavoidable previous to the time of the $x$-ray.

\section{A CERTAIN AND SIMPLE METHOD OF OBTAINING THE KNEE-JERK}

\section{CLRRAN POPE, M.D.} LOUISVILLE, KX.

In the study and investigation of neurologic cases. I am constrained to believe that the knee-jerk or patellar tendon reflex, correctly obtained, is one of the most important tests, if not the most important, in a great variety of cases. It is certainly a test that the general practitioner should more frequently make in the ordinary routine examinations of his practice. Perhaps not everyone is aware that the knee-jerk is often present, but inhibited by the patient, and that any method that will insure a correct response is well worth consideration. I have found it practically impossible for a patient to inhibit the knee-jerk if the method here described is employed. It was in an endeavor to prevent this frequent occurrence that the following plan was evolved.

The patient, male or female, should sit in an ordinary straight-backed office chair, relaxing the entire body as far as possible. The feet are then pushed forward so as to extend the lower limbs comfortably. This position produces complete relaxation of the flexor groups of muscles of the lower limbs, and, as it is these groups of muscles that inhibit the response. it seems rational to believe that the inhibition would be prevented.

With the limbs in the position indicated, and with the ends of the toes of both shoes on a line, the clothing is drawn reasonably snug over the patella with the thumb and forefinger of the left hand in right-handed individuals. The three remaining fingers and the palm of the hand should rest on the thigh just above the patella. With a percussion hammer a gentle tap is given the tendon and its response or the absence thereof can be both seen and felt, for the palm and three fingers of the left hand will give an excellent index of the prominence and activity of the response:

In this position, reinforcement is most satisfactorily performed, and a wider range of action obtained.

I have been unable to find a description of this method and, therefore, believe it to be original. It has stood me in good stead in some cases in which it was very important to know the presence or absence of this reflex.

115 West Chestnut Street.

\section{A DRUM-SPINNIING ATTACHMENT FOR AN ORDINARY KYMOGRAPHION}

\section{E. JACKSON, Pr.D.}

Associate in Pharmacology, Washington University Medical School ST. LOUIS

This attachment can be fastened to the base of a Harvard Apparatus Company's kymographion by means of a single thumb screw, as shown at. $A$ in the illustration. The device is "set" by pulling out the plunger by means of the ring $B$. When the knob $C$ is pulled the drum will be spun around rapidly for one revolution and then stopped in exactly the same position as that from which it started. The writing-points of all muscle levers,

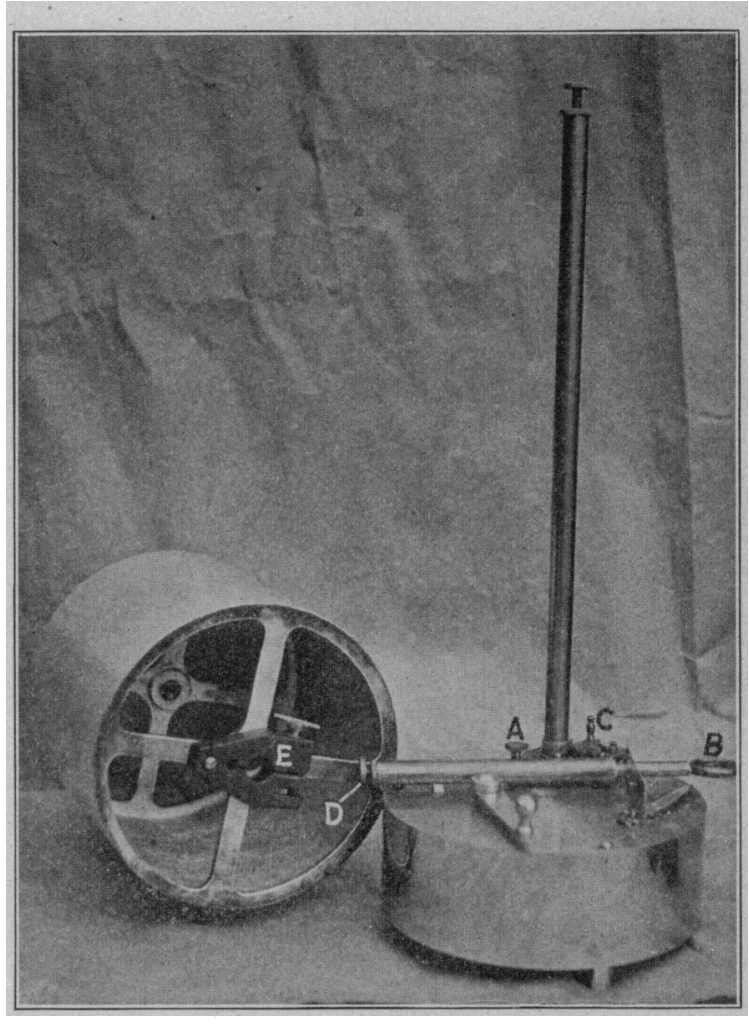

Drum-spinning attachment for an ordinary kymographion.

tuning-fork, etc., remain constantly on the even surface of the drum paper. The plunger can be at once "set" and the drum spun again as many times as desired, thus allowing superimposed curves to be taken on the same base line. A set-screw $D$ can be adjusted to regulate the speed at which the drum spins. A special clamp $E$ fastened to the lower part of the drum permits it to be firmly clamped on to the drum spindle. With slight variations in regard to the attachment this device may be used on any ordinary kymographion. It is generally desirable to fasten the kymograph down to the table by means of a small hand clamp.

This spinning device was made for me by Mr. Paul Bauer, mechanician for the Washington University Medical School. It answers the same purpose as the pendulum, or spring myograph, with the added advantages that it is smaller, cheaper, and much more easily and conveniently manipulated by students. 